\title{
Kabuki Make-Up Sendromu: Nadir Bir Olgu
}

\author{
Kabuki Make-Up Syndrome: A Rare Case
}

\author{
Ali KARAMAN ${ }^{1}$, Arda CCETINKAYA ${ }^{1}$, Selin KARAMAN ${ }^{2}$ \\ 1. SBÜ, Zeynep Kamil Kadın ve Çocuk Hastalıkları Eğitim ve Araştırma Hastanesi, Genetik Tanı Merkezi, İstanbul, Türkiye \\ 2. SBÜ, Ümraniye Ĕgitim ve Araştırma Hastanesi, Anestezi ve Reanimasyon Kliniği, İstanbul, Türkiye
}

\section{$\ddot{O Z Z E T}$}

Kabuki make-up sendromu, multipl konjenital anomaliler, tipik yüz görünümü, iskelet anomalisi, dermatoglifik degissiklikler, postnatal büyüme geriliği ve mental retardasyonla karakterize nadir bir sendromdur. Kabuki make-up sendromu, genellikle sporadik oluşan MLL2 ve KDM6A genindeki değișime bağlı doğumsal bir bozukluktur. Kabuki tipi yüz görünümü, gelişim geriliği, mental retardasyon, fetal parmak yastıkçıklarl olan Kabuki make-up Sendromlu bir olgu literatüre katkı amaclyla sunuldu.

Anahtar Kelimeler: kabuki make up, mental retardasyon

\section{ABSTRACT}

Kabuki Make-up Syndrome is a rare syndrome characterized by multiple congenital anomalies, typical with facial appearance, skeletal anomalies, dermatogliphic changes, postnatal growth failure and mental retardation. Kabuki Make-Up Syndrome is usually consisting of sporadic congenital disorder due to changes in MLL2 and KDM6A gene. We presented a case with typical features of Kabuki Make-Up Syndrome that has Kabuki type facial appearance, growth failure and mental retardation, fetal finger pads for contribute to the literature.

Keywords: kabuki make up, mental retardation

\section{GİRIŞ}

Kabuki make up sendromu (KMS) postnatal büyüme geriliği, karakteristik yüz yapısı ile seyreden otozomal dominant bir konjenital mental retardasyon sendromudur. Alt göz kapağının lateral 1/3'i dışa dönük ve uzun palpebral fissürler ile karakterize tipik yüz görünümü (Kabuki make-up), geniş ve deprese burun ucu, geniş ve belirgin kulak memesi, yüksek veya yarık damak, skolyoz, 5. parmak kısalığ1, fetal parmak yastıkçıkları, vertebra, el ve kalça ekleminde radyografik anormallikler, yenidoğan döneminde tekrarlayan otit atakları gibi ek bulgular içeren bir sendromdur (1).

\section{İletişim}

Sorumlu Yazar: Doç. Dr. Ali KARAMAN

Adres: SBÜ, Zeynep Kamil Kadın ve Çocuk Hastalıkları Eğitim ve Araștırma Hastanesi, Genetik Tanı Merkezi, İstanbul, Türkiye

Tel: $+90(505) 7897451$

E-Posta: alikaramandr@hotmail.com

Makale Geliş: 10.09.2018

Makale Kabul: 09.02.2019

DOI: http://dx.doi.org/10.16948/zktipb.458645
KMS ismini, etkilenmis bireylerin tipik yüz görünümü, geleneksel Japon tiyatrosu Kabuki'deki aktörlerin makyajına benzemesinden almaktadir. KMS tip-1 (KABUK1) 12q12-q14 bölgesinde bulunan MLL2 genindeki heterozigot mutasyona bağlı oluşmaktadır (2, 3). Kabuki sendromu tip-2 ise Xp11.3 bölgesinde buluınan KDM6A genindeki mutasyona bağlı oluşmaktadır $(4,5)$. Bu yazıda fizik muayene bulguları nedeniyle tipik Kabuki Make Up Sendromu düşünülen bir hasta literatür bilgileri 1şı̆̆ında tartışılarak sunulmuştur.

\section{OLGU}

Olgu aralarında akrabalık olmayan 26 yaşında sağlıklı baba ve 25 yaşında sağlıklı annenin ilk gebeliklerinden doğan çocuklarıydı. Miadında normal yolla $2850 \mathrm{gr}$ ağırlığında, $49 \mathrm{~cm}$ boyunda ve $34 \mathrm{~cm}$ baş çevresiyle doğmuştu. Olgunun postnatal adaptasyon problemi olmamış ve göze çarpan bir anomalisi yokmuş.

Gelişim geriliği ve dismorfik yüz görünümü nedeniyle birimimize yönlendirilmiş. Başvuru s1rasında 4 yaşında olan olgu $13 \mathrm{~kg}$ (3-10 p.) kilo ve $90 \mathrm{~cm}(<3$ p.) boyundayd1. Konuşma geriliği olan hastanın yapılan DENVER II gelişim testinde dil gelişim geriliğiyle beraber hafif mental retardasyon tespit edildi. Fizik muayenesinde geniş alın, belirgin metopik sutur, kaşlar yay şeklinde, yukarı çekik gözler, göz ve kaş arası mesafede belirgin artış, uzun palpebral aralık, telekantus, sağ gözde hafif pitozis ve pozisyonel şaşılık, kalın alt dudak, çürük ve düzensiz dişler, mikrognati, retrognati, kulaklar hafif geride ve düşük yerleşimli, el ve ayak parmaklarında fetal parmak yastıkçıkları, bilateral el ve ayak 5. parmak klinodaktilisi ve hafif eklem hiperekstansibilitesi saptandı (Şekil 1, 2).

Ekstremite ve vertebra X-Ray grafilerinde herhangi bir patoloji saptanmadi. Sol el bilek grafisinde kemik yaşı ölçümü 2,5 yaş ile uyumlu bulundu. Yapılan kranial MR incelemesinde solda belirgin olmak üzere her iki temporal lop düzeyinde periferik bos mesafesinde genişleme, her iki temporal lopda hafif volüm kayb1, korpus kallozum BOS ve splenium ile uyumlu kesimi disgenetik görünümde, temporal lop, parietal loplar düzeyinde kortekste diffüz kalınlık artıșı pakigri ile uyumlu olabilecek görünüm saptand1. Olgunun tüm batın USG incelemesinde batın içi organlarda, gastrointestinal ve üriner sisteme ait herhangi bir patoloji saptanmadi.

Yaptığımız konvansiyonel karyotip analizinde 46, XY kromozom yapisina sahipti. 


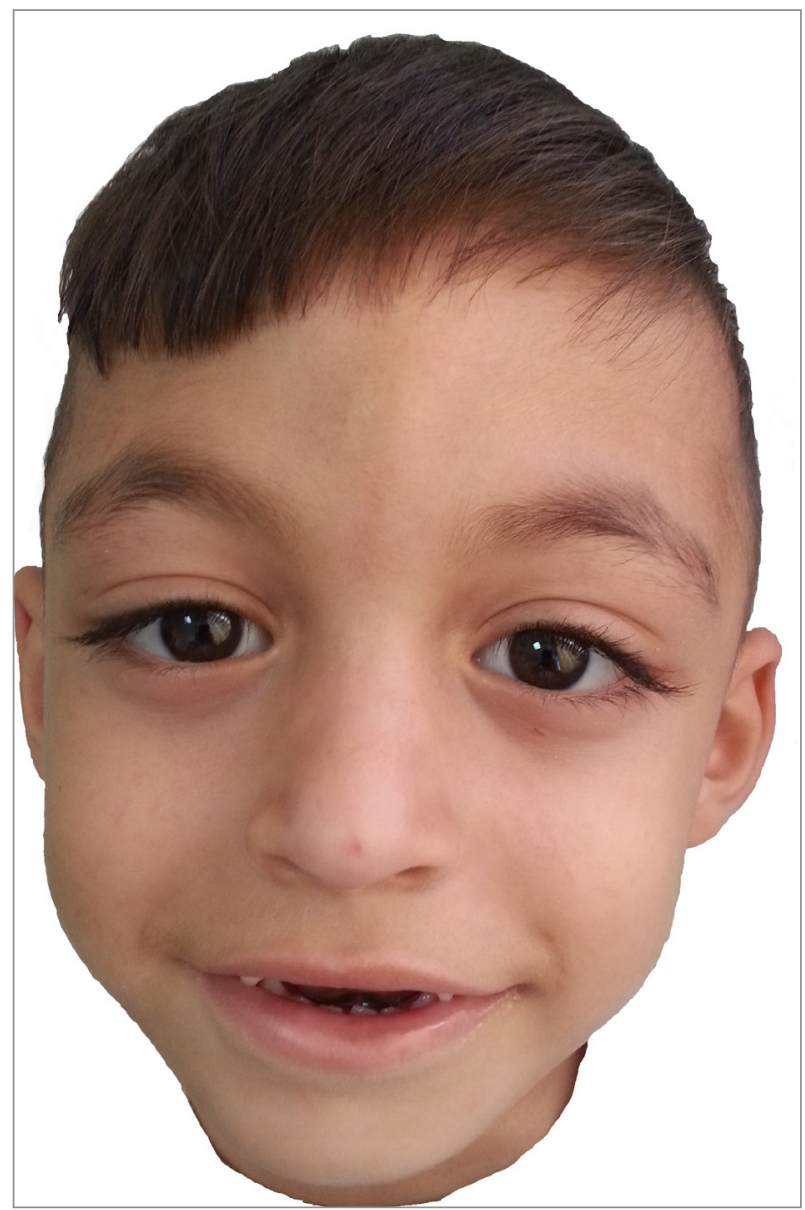

Şekil 1

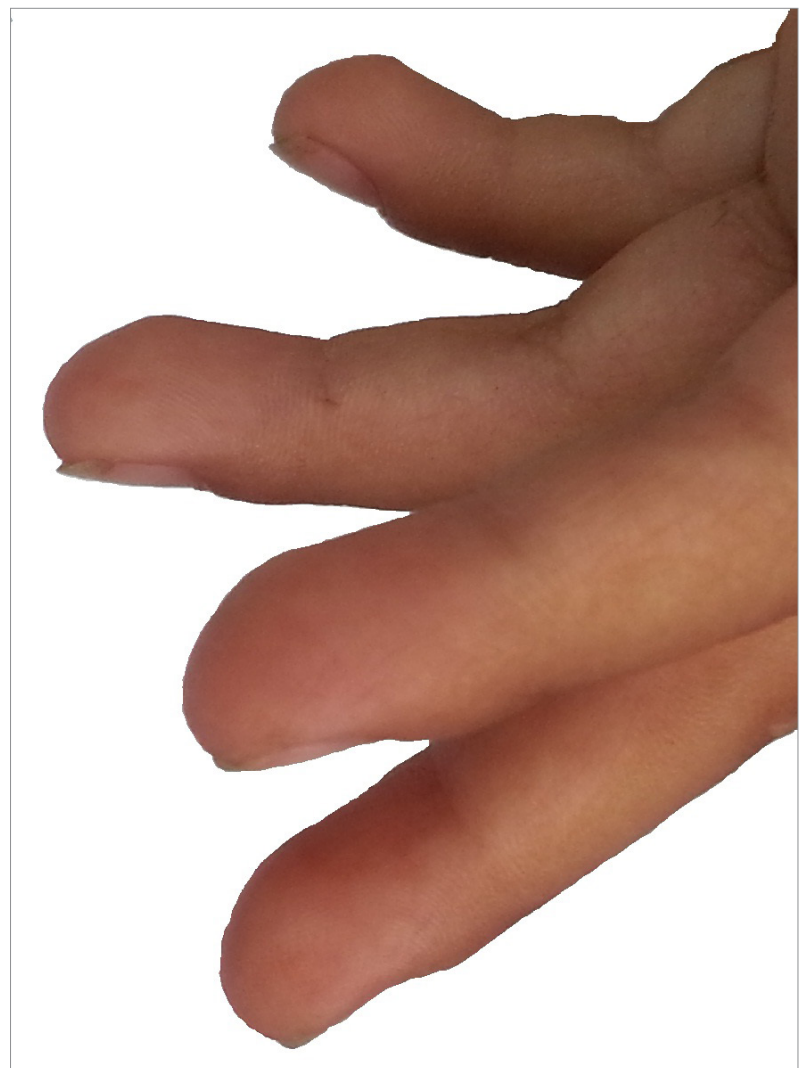

Şekil 2

TARTIŞMA

KMS ilk olarak Niikawa ve ark. tarafindan 1981 yılında aralarında akrabalık bulunmayan 10
Japon çocuğunda tanımlanmıștır.1 Niikawa ve arkadaşları 1988 yılında yaptıkları bir çalışmada da çoğunluğu Japon olan 62 hastanın verilerini topladılar. Hastaların büyük kısmında 5 kardinal bulgu tanımladılar: (1) tüm olgularda alt göz kapağının lateralinde eversiyon, lateral 1/3'inde seyreklik olan yay şeklinde kaşlar, basık burun ucu, belirgin kulaklarla karakterize tipik yüz görünümü; (2) \%92'sinde 5. parmak kısalığ1 ve yarık vertebranın eşlik ettiği veya etmediği vertebral deformiteleri içeren iskelet anomolileri; (3) \%93'ünde fetal parmak yastıkç1klarını içeren dermatoglifik değișiklikler, (4) \%92'sinde hafif-orta mental retardasyon, ve (5) \%83'ünde postnatal büyüme geriliği (6).

Süt çocukluğu döneminde k1z bebeklerin \%23'ünde erken meme gelişimi görülebilmektedir. Hastaların \%31'inde tek ventrikül, ventriküler septal defekt, atrial septal defekt, Fallot tetralojisi, aort koarktasyonu, patent duktus arteriosus, aort anevrizması, büyük arterlerin transpozisyonu ve sağ dal bloğu gibi konjenital kalp defektleri gözlenebilmektedir. 62 Kabuki sendromu hastasının 58'i Japon kökenli idi. Japon yenidoğanlarda hastalığın insidans1 1/32.000 olarak hesaplandı. Tüm vakaların sporadik olduğu saptanmıştır. Genel olarak Naiikawa ve arkadaşlarının bulguları her hastada yeni gelişen bir mutasyona bağlı oluşmuş otozomal dominant bir hastalığg düşündürmüştür (6).

Ünalp ve Giray 2008 yılında gelişme geriliği, unutkanlık, aşırı hareketlilik, konuşma bozukluğu, nöromotor gelişim geriliği, ağır derecede zekâ geriliği (ortalama IQ=48), EEG'sinde jeneralize paroksismal anormallik saptanan, tekrarlayan otitis media atakları yaşayan bir erkek olgu tanımlamıştır (7).

Sertçelik ve arkadaşları KMS'lu bir olguda otizim spektrum bozukluğunu ifade etmiştir (8).

Olgumuzda KMS kardinal bulgularından 2 . bulgu olan iskelet anomalisi hariç diğer bulgular mevcuttu. Ancak iskelet anomalisi olarak kabul etmediğimiz 5. parmak kısalığ 1 eşlik etmekteydi. Bu durum olgumuzun kabuki sendromu için gerekli kriterlerin çoğunluğunu fenotipik olarak gösterdiğini kanıtlamaktadır. Ailede benzer yüz fenotipi başka kimsede olmaması ve ebeveynler arasında akrabalık bulunmaması hastamızın sporadik otozomal dominant kalıtım modelini desteklediğini göstermektedir.

Ng ve arkadaşları 2010 yılında, 7'si Avrupa11, 2'si Íspanyol, 1'i Avrupa-Haiti li olmak üzere 10 KMS'lu hastanın ekzom sekanslarını gerçekleştirdiler ve 7 hastada MLL2 geninde anlamsız veya çerçeve kayması mutasyonu tespit ettiler. Daha sonra yapılan Sanger sekansı ile geriye kalan 3 hastanın ikisinde ve 43 ek KMS vakasinin 26'sinda MLL2 mutasyonu saptadılar. Tüm vakalar değerlendirildiğinde 53 Kabuki sendromu hastasının 35'inde 33 farkl1 MLL2 mutasyonu saptadilar ve MLL2 genindeki mutasyonların Kabuki sendromunun majör sebebi olduğunu tespit ettiler (9).

Banka ve arkadaşları KMS tanılı ve 18'i daha önce bildirilen 116 hastanın kohort çalışması ile MLL2 gen analizini yapmış ve 74 hastada $(\% 63,8)$ MLL2 varyantları tespit etmiştir. Sistematik Kabuki sendromu yüz morfolojisi çalışması göstermiştir ki tipik Kabuki sendromu yüz görünümüne sahip olan 
neredeyse tüm hastalar patolojik MLL2 mutasyonunu taşımaktadır, ancak hastalık fenotipik olarak farklılıklar gösterebilmektedir. Ek olarak çalışmada MLL2 mutasyonu pozitif olan hastaların, negatif hastalarla karşılaștırıldığında daha fazla beslenme problemleri, böbrek anomalileri, erken meme gelişimi, eklem dislokasyonu ve palatal malformasyonlara sahip olduğunu göstermiştir. Sonuç olarak çalışmada KMS'nun genetik heterojenitesinin daha önceden düșünüldüğü kadar yoğun olmadığ1; hastalığın fenotipik değişkenliği olsa da atipik hastalarda dahi MLL2 çalışmasının değerlendirilmesi gerektiğini öne sürmüşlerdir $(10,11)$.

Lederer ve arkadaşları, MLL2 mutasyonu negatif olarak tespit edilen birbiriyle akraba olmayan KMS'lu iki Belçikalı kız çocuğunun array CGH analizi sonucu, her ikisinde de KDM6A genini k1smen veya tamamını kapsayan, de novo Xp11.3 mikrodelesyonu tespit etmiştir. KDM6A genindeki delesyonların, MLL2 mutasyonu negatif olan hastalarda Kabuki sendromu ile ilişkili olabileceğini göstermiştir (12).

Olgu, tipik yüz yapısı, mental geriliği, hastalikla uyumlu diğer fizik muayene bulguları ile Kabuki Sendromu olarak değerlendirildi. $\mathrm{Bu}$ yazıda Kabuki sendromlu bir olgu ve tartışması literatüre katk1 amaciyla sunuldu.

\section{KAYNAKLAR}

1. Niikawa N, Matsuura N, Fukushima Y, Ohsawa T, Kajii T. Kabuki make-up syndrome: a syndrome of mental retardation, unusual facies, large and protruding ears, and postnatal growth deficiency. J Pediat 1981; 99: 565-9.

2. Van Laarhoven PM, Neitzel LR, Quintana AM, Geiger EA, Zackai EH, Clouthier DE, Artinger KB, Ming JE, Shaikh TH. Kabuki syndrome genes KMT2D and KDM6A: functional analyses demonstrate critical roles in craniofacial, heart and brain development. Hum Mol Genet. 2015 ;1;24(15):4443-53. doi: 10.1093/hmg/ddv180.

3. Lehman N, Mazery AC, Visier A, Baumann C, Lachesnais D, Capri Y, et al. Molecular, clinical and neuropsychological study in 31 patients with Kabuki syndrome and KMT2D mutations. Clin Genet. 2017;92(3):298-305. doi: 10.1111/cge.13010.

4. Liu S, Hong $X$, Shen $C$, Shi $Q$, Wang J, Xiong $F$, Oiu Z. Kabuki syndrome: a Chinese case series and systematic review of the spectrum of mutations. BMC Med Genet. 2015: 21;16:26. doi: 10.1186/s12881-015-0171-4.

5. Bogershausen N, Bruford E, Wollnik B. Skirting the pitfalls: a clear-cut nomenclature for H3K4 methyltransferases. Clin Genet. 2013;83(3):212-4.

6. Niikawa N, Kuroki Y, Kajii T, et al. Kabuki make-up (Niikawa-Kuroki) syndrome: a study of 62 patients. Am J Med Genet 1988; 31: 565-89.

7. Ünalp A, Giray Ö. Kabuki-Make Up Sendromu: Olgu Sunuтu. DEÜ Tip Fakültesi Dergisi 2008; 22 (1): 23-26.

8. Sertçelik M, Uğur Ç, Şahin Aközel A, Gürkan CK. A Child with Kabuki Syndrome and Autism Spectrum Disorder. Noro Psikiyatr Ars. 2016; 53(3): 280-282. doi: 10.5152/npa.2015.10099.

9. $\mathrm{Ng} S B$, Bigham AW, Buckingham KJ, et al. Exome sequencing identifies MLL2 mutations as a cause of Kabuki syndrome. Nature Genet 2010; 42: 790-3. doi: 10.1038/ng.646
10. Hannibal MC, Buckingham KJ, Ng SB, et al. Spectrum of MLL2 (ALR) mutations in 110 cases of Kabuki syndrome. Am J Med Genet 2011; 155A: 1511-6. doi: 10.1002/ajmg.a.34074

11. Banka S, Veeramachaneni R, Reardon W, et al. How genetically heterogeneous is Kabuki syndrome? MLL2 testing in 116 patients, review and analyses of mutation and phenotypic spectrum. Europ J Hum Genet 2012; 20: 381-8. doi: 10.1038/ ejhg. 2011.220

12. Lederer D, Grisart B, Digilio MC, et al. Deletion of KD$M 6 A$, a histone demethylase interacting with MLL2, in three patients with Kabuki syndrome. Am J Med Genet 2012; 90: 119-24. doi: 10.1016/j.ajhg.2011.11.021. 